\title{
Correlation between Choline Level and Gd-DTPA Enhancement in Patients with Brain Metastases of Mammary Carcinoma
}

\author{
Paul E. Sijens, Pieter van Dijk, Matthijs Oudkerk
}

\begin{abstract}
Single voxel ${ }^{1} \mathrm{H}$ double spin-echo MR spectroscopy was used to examine 15 cases of brain metastasis of mammary carcinoma (18 lesions) in relation to Gd-DTPA enhanced MR imaging. For lesions larger than $\mathbf{5 0} \%$ of MRS voxel size, there was significant correlation between Gd-DTPA-enhanced MRI signal and MRS-detected signal of choline (Cho) containing compounds $(r=0.86, P<0.01 ; n=8)$. The observed loss of correlation when including the smaller lesions was overcome by correcting for partial volume effects $(r=0.69, P<0.002$; $n=18$ ). Metastasis spectra showed increased Cho compared with control spectra, except for those lesions showing detectable lactate (Lact) signal. The detection of Lact in four of the larger lesions coincided with comparatively low levels of creatine (Cr) and Cho and heterogeneous Gd-DTPA enhancement (ring-enhancement). It was concluded that in brain metastases of mammary carcinoma Lact represents a product of ischemia preceding/during tissue decay resulting in central necrosis, rather than tumor specific metabolism resulting in increased glycolysis.
\end{abstract}

Key words: brain metastases; Gd-DTPA contrast agent; magnetic resonance imaging; magnetic resonance spectroscopy.

\section{INTRODUCTION}

Gd-DTPA is the most frequently used contrast agent in brain MR imaging (1-3). The $T_{1}$ shortening metal chelate distributes primarily in the intravascular, extracellular space and quickly passes into the extravascular, interstitial space (4). Used intravenously it provides contrast enhancement in $T_{1}$-weighted MR images of intracranial lesions associated with an abnormal vascular bed, as is the case in metastatic lesions, or breakdown of the bloodbrain barrier (BBB) as is generally the case in the more malignant primary brain tumors (5). Metastatic lesions possess non-CNS capillaries similar to their tissues of origin, so brain metastases virtually always enhance. The use of Gd-DTPA for CNS applications has become routine in distinguishing the extent of lesions from peritumor edema and in detecting residues, recurrence, and growth of primary tumors and metastases $(2,6)$. However, there

MRM 32:549-555 (1994)

From the Dr. Daniel den Hoed Cancer Center (DDHCC), Groene Hilledijk 301, P.O. Box 5201, 3008 AE Rotterdam, The Netherlands.

Address correspondence to: Paul E. Sijens, Ph.D., Department of Radiology, Dr. Daniel den Hoed Cancer Center (DDHCC), Groene Hilledijk 301, P.O. Box 5201, 3008 AE Rotterdam, The Netherlands.

Received January 26, 1994; revised July 18, 1994; accepted July 18, 1994 Parts of this work were accepted for oral presentation at the 13th Annual Meeting of the Society of Magnetic Resonance in Medicine, held in New York, NY, August 1993 and at the 12th Annual Meeting of the Society for Magnetic Resonance Imaging, held in Dallas, TX, March 1994. 0740-3194/94\$3.00

Copyright (C) 1994 by Williams \& Wilkins

All rights of reproduction in any form reserved. has been confusion whether necrotic tissues are specifically enhanced with Gd-DTPA $(4,7,8)$ or to the contrary that the necrotic regions in tumors show up as hypointense areas $(9,10)$.

Localized ${ }^{1} \mathrm{H}$ MR spectra of normal brain tissue measured under suppression of the water signal show the resonances of Cho, Cr, and NAA. The Cr peak includes both creatine and phosphocreatine signal and there are still unanswered questions regarding what compounds contribute to the Cho and NAA peaks (11). Brain tumors have relatively high Cho levels and reduced NAA levels (12-19). Whereas Cho level generally increases with tumor size, it cannot be used as a discriminator of tumor grade because necrotic high grade tumors have low levels of Cho (20). Metabolic heterogeneity of human intracranial tumors has been shown $(18,20-22)$. Some authors have suggested that Lact is concentrated in necrotic tissue $(13,16)$ or peritumoral edema $(22)$ as opposed to others who correlated the presence of Lact with increased glucose uptake (18).

${ }^{1} \mathrm{H}$ MRS publications to date have focused on the larger brain lesions such as (high grade) primary brain tumors. Brain metastases are generally small and therefore more difficult to characterize by MRS. Single volume MRS was used in this study because of the better quality lesion spectra obtained after shimming on small volumes compared with the results of spectroscopic imaging methods, which require shimming on larger volumes to obtain arrays of spectra including the lesion. To our knowledge ${ }^{1} \mathrm{H}$ MRS studies including more than a single case of mammary carcinoma brain metastasis have not been published. New in this study is also the correlation of the ${ }^{1} \mathrm{H}$ MRS measured metabolic profiles of brain lesions with Gd-DTPA-enhanced MR imaging.

\section{MATERIALS AND METHODS}

Fifteen patients with untreated brain metastases of mammary carcinoma, all showing Gd-DTPA-induced signal enhancement in $T_{1}$-weighted MRI, were examined by ${ }^{1} \mathrm{H}$ MRS. MR examinations were performed at $1.5 \mathrm{~T}$ using a 1.5/2 T SP63/84 Helicon whole-body MR scanner (Siemens AG, Erlangen, Germany). The standard circular polarized transmit/receive head coil and $10 \mathrm{mT} / \mathrm{m}$ gradient system were used for both MRI and MRS.

\section{Gd-DTPA Enhanced MR Imaging}

MRI studies, preceding the MRS by up to 2 weeks, were performed with a $T_{1}$-weighted sequence (TR/TE 600/15, 2 NEX, matrix size $192 \times 256,3 / 4$ rectangular FOV) and 
a $T_{2}$-weighted sequence ( $T R / T E$ 2000/12-80), $1 \mathrm{NEX}$, matrix size $192 \times 256,3 / 4$ rectangular FOV) in $6-\mathrm{mm}$ slices. $T_{1}$-weighted MRI was repeated $5 \mathrm{~min}$ after administration of Gd-diethylenetriamine pentaacetic acid-dimeglumine (0.2 mmol Gd-DTPA/kg; Schering AG, Berlin, Germany). Brain metastases do not show significant (further) enhancement at later times post-Gd-DTPA contrast (P. van Dijk and M. Oudkerk, works in progress). Routines provided by the manufacturer of the MR system were used to determine the mean signal intensities and standard deviations for the largest transverse 6-mm thickness MRI cross section of each lesion.

\section{Localized 'H MR Spectroscopy}

The use of stimulated echo (STEAM) spectroscopy to select a VOI reliably as well as to suppress the unwanted water signal in a single experimental step has been described in detail (23). In this study the double spin-echo (DSE) sequence rather than the STEAM sequence was used because in our experience the gain in signal is close to the reported $90 \%$ (24). In phantom experiments, artifacts due to acetate or Lact signals from outside the VOI were not larger than expected from the calculated chemical shift artifacts of 0.074 and $0.037 \mathrm{~cm} / \mathrm{ppm}$ at the used slice selection gradients of $2 \mathrm{mT} / \mathrm{m}$ (for selecting volumes of $8-36 \mathrm{~cm}^{3}$ ) and $4 \mathrm{mT} / \mathrm{m}$ (for volumes between 1 and 8 $\mathrm{cm}^{3}$ ), respectively. Care was taken to ensure proper positioning of lesion MRS voxels in those regions that had shown signal enhancement in the Gd-DTPA-enhanced MRI studies (previous paragraph). Analysis of patient spectra was confined to Cho (chemical shift $3.21 \mathrm{ppm}$ ), Cr (3.02 ppm), NAA (2.01 ppm), and Lact (doublet centered at $1.32 \mathrm{ppm}$ with coupling constant of $7 \mathrm{~Hz}$ ) peak integrals. Lipid signals were not quantitated because in peripheral voxels contributions from nonspoiled subcutaneous fat signals were often significant. The presented MRS data and the spectra shown in the figures were all acquired with $T E=135 \mathrm{~ms}$. At $T E=135 \mathrm{~ms}$, due to $J$ modulation, the doublet signal of Lact is inverted $\left(180^{\circ}\right.$ out of phase) relative to the singlets of $\mathrm{Cho}, \mathrm{Cr}$, and NAA (25). To confirm the identity of presumed Lact peaks, MRS measurements were repeated with $T E=270 \mathrm{~ms}$ (Lact doublet in phase). The whole procedure including sagittal and transverse MRI, global shimming, volume selection, local shimming, water suppression optimization and the measurement of two voxels took $60 \mathrm{~min}$. The acquisition of a sagittal localizer was followed by proton density and $T_{2}$-weighted imaging (1500/12-80) using a $55^{\circ}$ flip angle, 15 slices of $6 \mathrm{~mm}$ without a slice gap, a $128 \times 256$ matrix and 1 acquisition ( $3.15 \mathrm{~min}$ ). The field homogeneity achieved in global and local shimming resulted in water peak line widths of at most $17 \mathrm{~Hz}$ and 6 $\mathrm{Hz}$, respectively. SE MR spectra were collected with 2.56-ms sinc-shaped RF pulses preceded by $25.6 \mathrm{~ms}$ Gaussian-shaped RF pulses for chemical shift selective excitation (CHESS) and subsequent spoiling of the resultant water signal. The second half of the spin echo was collected using 1024 data points and a spectral width of $500 \mathrm{~Hz}$. All DSE measurements of voxels that varied in size between 1 and $36 \mathrm{~cm}^{3}$, were the sum of 256 acqui- sitions with four prescans and $T R=1600 \mathrm{~ms}$ (acquisition time $6.57 \mathrm{~min}$ ). Typically time domain data were zerofilled to 4096 points, multiplied with a Gaussian function (center $0 \mathrm{~ms}$, half width $256 \mathrm{~ms}$ ), Fourier transformed, phase corrected and fitted to Lorentzian curves. Because the gradient-induced artifacts in amplitude and phase of the localized RF pulses were minor, the spectra were already of good quality when not corrected for the effects of eddy currents. All MRS data were therefore processed without introducing an additional source of error in the form of eddy current compensation.

A pilot study on six healthy volunteers (aged between 22 and 41 years) demonstrated a fairly constant ratio between the total metabolite signals detected in the occipital lobe $\left(8 \mathrm{~cm}^{3}\right.$ voxel) and in caput nuclei caudati (also $8 \mathrm{~cm}^{3}$ ), that is $1.09 \pm 0.29 \mathrm{SD}$. To get semiquantitative data, metabolite levels have been presented as percentages of the NAA level measured in the contralateral occipital voxel. The same normalizations were made by others $(14,26)$. Ratios of Cho to NAA and $\mathrm{Cr}$ to NAA of $38 \pm 6$ and $51 \pm 13$ (percentages \pm SD; occipital lobe) and $52 \pm 10$ and $47 \pm 10$ (corpus nuclei caudati) in the healthy volunteer study, confirmed the good reproducibility of the MR spectra. Lesion voxels and occipital control voxels had the same dimensions, except for lesion voxels larger than $8 \mathrm{~cm}^{3}$ (the largest cubic volume not exceeding the dimensions of the occipital lobes of the brain). In the latter case differences in voxel size were accounted for by normalization.

\section{Statistics}

Correlation analyses were applied and Student's $t$ test, two-tailed, was used in the assessment of the significances of the presented linear correlations and of differences between group means.

\section{RESULTS}

The ${ }^{1} \mathrm{H}$ MRS characteristics of the examined metastases of mammary carcinoma are summarized in Table 1 . Voxels varying in size between 1 and $36 \mathrm{~cm}^{3}$ were selected to include the whole abnormality. With respect to their $T_{1}$ weighted MRI behavior on addition of Gd-DTPA, lesions could be divided in two categories: (1) more or less homogeneously enhancing (Cases 1, 2, 3b, 4-9, 11-13, 15) and (2) ring-enhancing, that is nonenhancing areas surrounded by an enhancing shell (Cases 3a, 10,14). In Table 1 lesion contrast is presented as percent difference between mean lesion signal and normal tissue signal at the largest MRI cross section (6-mm slice thickness), and lesion heterogeneity by the included standard deviations. There was a significant linear correlation between total lesion volume as estimated from postcontrast MRI series, and signal heterogeneity $(r=0.59, P<0.02 ; n=18)$.

MRS detected metabolite levels are presented in Table 1 as percentages of the integrated NAA signal in the contralateral occipital voxel measured in the same patient examination. Lesion-containing voxels generally revealed high Cho, normal $\mathrm{Cr}$, and reduced NAA levels compared with the control voxels, which had Cho to 
Table 1

Gd-DTPA Enhancement and ${ }^{1} \mathrm{H}$ MR Spectroscopy Measured Metabolite Levels in Brain Metastases of Mammary Carcinoma

\begin{tabular}{|c|c|c|c|c|c|c|c|c|c|c|c|c|c|c|}
\hline \multirow{2}{*}{ Case } & \multicolumn{2}{|c|}{ Gd-DTPA enhancement MRI } & \multirow{2}{*}{$\begin{array}{l}\text { MRS } \\
\text { voxel } \\
\text { size } \\
\left(\mathrm{cm}^{3}\right)\end{array}$} & \multicolumn{4}{|c|}{$\begin{array}{l}\text { MRS detected } \\
\text { metabolite } \\
\text { levels }^{d}\end{array}$} & \multicolumn{3}{|c|}{$\begin{array}{l}\text { Lesion } \\
\text { metabolite } \\
\text { levels }^{\ominus}\end{array}$} & \multicolumn{3}{|c|}{$\begin{array}{l}\text { Lesion metabolite levels } \\
\text { divided by filling factor }\end{array}$} & \multirow{2}{*}{ Lipid $^{9}$} \\
\hline & $\begin{array}{c}\text { Lesion } \\
\text { volume }\left(\mathrm{cm}^{3}\right)^{\mathrm{a}}\end{array}$ & $\begin{array}{l}\text { Contrast } \\
\pm \mathrm{SD}^{\mathrm{c}}\end{array}$ & & Cho & $\mathrm{Cr}$ & NAA & Lact & Cho & $\mathrm{Cr}$ & Lact & Cho & $\mathrm{Cr}$ & Lact & \\
\hline 1 & 6.2 & $25 \pm 8$ & 8 & 65 & 20 & 18 & 0 & 56 & 11 & 0 & 72 & 14 & 0 & + \\
\hline 2 & 1.3 & $29 \pm 6$ & 8 & 73 & 47 & 75 & 0 & 35.5 & 9.5 & 0 & 218 & 58 & 0 & - \\
\hline $\begin{array}{r}3 a \\
b\end{array}$ & $\begin{array}{l}7 \\
1.1\end{array}$ & $\begin{aligned}-13 & \pm 24 \\
2 & \pm 5\end{aligned}$ & $\begin{array}{l}8 \\
3.4\end{array}$ & $\begin{array}{l}48 \\
40\end{array}$ & $\begin{array}{l}25 \\
28\end{array}$ & $\begin{array}{l}33 \\
42\end{array}$ & $\begin{array}{r}61 \\
0\end{array}$ & $\begin{array}{l}31.5 \\
19\end{array}$ & $\begin{array}{l}8.5 \\
7\end{array}$ & $\begin{array}{r}61 \\
0\end{array}$ & $\begin{array}{l}36 \\
59\end{array}$ & $\begin{array}{l}10 \\
22\end{array}$ & $\begin{array}{r}70 \\
0\end{array}$ & $\begin{array}{l}+ \\
-\end{array}$ \\
\hline $\begin{array}{r}4 a \\
b\end{array}$ & $\begin{array}{l}12 \\
0.4\end{array}$ & $\begin{array}{l}46 \pm 12 \\
28 \pm 9\end{array}$ & $\begin{array}{l}18 \\
18\end{array}$ & $\begin{array}{l}168 \\
129\end{array}$ & $\begin{array}{l}53 \\
64\end{array}$ & $\begin{array}{r}68 \\
112\end{array}$ & $\begin{array}{l}0 \\
0\end{array}$ & $\begin{array}{r}134 \\
73\end{array}$ & $\begin{array}{r}19 \\
8\end{array}$ & $\begin{array}{l}0 \\
0\end{array}$ & $\begin{array}{r}201 \\
3285\end{array}$ & $\begin{array}{r}29 \\
360\end{array}$ & $\begin{array}{l}0 \\
0\end{array}$ & $\begin{array}{c}++ \\
-\end{array}$ \\
\hline 5 & 0.07 & $82 \pm 6$ & 8 & 48 & 59 & 67 & 0 & 14.5 & 25.5 & 0 & 1657 & 2914 & 0 & - \\
\hline 6 & 2.6 & $47 \pm 12$ & 27 & 84 & 89 & 100 & 0 & 34 & 39 & 0 & 353 & 143 & 0 & + \\
\hline 7 & 3.1 & $96 \pm 10$ & 8 & 66 & 10 & 0 & 0 & 66 & 10 & 0 & 170 & 3 & 0 & - \\
\hline 8 & 4.2 & $87 \pm 27$ & 8 & 199 & 19 & 25 & 0 & 186.5 & 6.5 & 0 & 355 & 12 & 0 & ++ \\
\hline 9 & 3.6 & $90 \pm 26$ & 8 & 103 & 48 & 74 & 0 & 66 & 11 & 0 & 147 & 24 & 0 & + \\
\hline 10 & 12 & $-6 \pm 51$ & 22.5 & 19 & 17 & 29 & 15 & 4.5 & 2.5 & 15 & 8 & 5 & 28 & + \\
\hline 11 & 1.4 & $26 \pm 7$ & 3.4 & 78 & 37 & 17 & 0 & 69.5 & 28.5 & 0 & 169 & 69 & 0 & ++ \\
\hline 12 & $19^{h}$ & $65 \pm 18$ & 8 & 97 & 10 & 10 & 35 & 92 & 5 & 35 & 115 & 6 & 44 & - \\
\hline $\begin{array}{r}13 a \\
b\end{array}$ & $\begin{array}{l}8.6 \\
5.0\end{array}$ & $\begin{array}{l}71 \pm 28 \\
34 \pm 17\end{array}$ & $\begin{array}{r}27 \\
8\end{array}$ & $\begin{array}{l}43 \\
76\end{array}$ & $\begin{array}{l}67 \\
47\end{array}$ & $\begin{array}{l}34 \\
53\end{array}$ & $\begin{array}{l}0 \\
0\end{array}$ & $\begin{array}{l}26 \\
49.5\end{array}$ & $\begin{array}{l}50 \\
20.5\end{array}$ & $\begin{array}{l}0 \\
0\end{array}$ & $\begin{array}{l}82 \\
79\end{array}$ & $\begin{array}{r}157 \\
33\end{array}$ & $\begin{array}{l}0 \\
0\end{array}$ & $\begin{array}{l}++ \\
++\end{array}$ \\
\hline 14 & 22 & $17 \pm 35$ & $\begin{array}{r}36 \\
8^{i}\end{array}$ & $\begin{array}{l}55 \\
53\end{array}$ & $\begin{array}{r}50 \\
7\end{array}$ & $\begin{array}{l}48 \\
10\end{array}$ & $\begin{array}{l}37 \\
72\end{array}$ & $\begin{array}{l}31 \\
48\end{array}$ & $\begin{array}{r}26 \\
2\end{array}$ & $\begin{array}{l}37 \\
72\end{array}$ & $\begin{array}{l}51 \\
48\end{array}$ & $\begin{array}{r}43 \\
2\end{array}$ & $\begin{array}{l}61 \\
72\end{array}$ & $\begin{array}{l}- \\
-\end{array}$ \\
\hline 15 & 0.3 & $49 \pm 13$ & 1 & 45 & 49 & 58 & 0 & 16 & 20 & 0 & 53 & 67 & 0 & - \\
\hline
\end{tabular}

aTotal lesion volume estimated from postcontrast MRI series.

bLesion contrast, i.e., percent difference between postcontrast lesion signal (at largest MRI cross-section) and the signal of contralateral brain tissue.

qesion heterogeneity, standard deviation in postcontrast lesion MRI signal in percentage of contralateral brain tissue signal.

dNormalized to the NAA level in contralateral occipital voxels (set at 100).

${ }^{e}$ Calculated by subtracting the normal brain tissue contributions from the overall ${ }^{1} \mathrm{H}$ MRS detected signals shown in previous columns

fufilling factor," lesion volume/MRS voxel size.

gabsent $(-)$, low $(+)$, high $(++)$.

"Major part of lesion located extracerebral.

'Center of the same lesion.

NAA and Cr to NAA ratios similar to those encountered in healthy volunteers (Cho $=38 \pm 6$ and $\mathrm{Cr}=51 \pm 13 \mathrm{SD}$ relative to NAA $=100$ ). The ${ }^{1} \mathrm{H}$ MR spectrum of a voxel containing a typical brain metastasis of mammary carcinoma (Case 2) is shown in Fig. 1. The level of Cho is mildly increased, Cr within the normal range and NAA slightly decreased; Lact is not detected. The Gd-DTPAenhanced MRI of the same lesion shows a small area of comparatively homogeneous signal enhancement. The mean MRI signal intensity in the whole enhanced area was $610 \pm 60 \mathrm{SD}$ arbitrary units (AU) compared with $472 \pm 9 \mathrm{AU}$ in contralateral brain tissue. The percent difference between both values, $29 \%$, is listed in Table 1 ("contrast"). Lesion center signal was measured in a circular ROI covering half the total area ( $637 \pm 28 \mathrm{AU})$. The quotient between the latter standard deviation, not influenced by the signal drop on the outer rim, and control signal was used as measure of lesion heterogeneity: 28/ $472=0.06$ or $6 \%$ (Case 2, Table 1). The results for a large brain metastasis showing more heterogeneous Gd-DTPA enhancement are shown in Fig. 2 (Case 4a). The level of Cho in the voxel containing the metastasis is very high, $168 \%$ of control NAA level. Lact was not detected. The third example is a large brain metastasis showing highly heterogeneous Gd-DTPA enhancement, "ring-enhance- ment," in $T_{1}$-weighted MRI (Fig. 3, Case 14). The Cho level, $55 \%$ of control NAA, is comparatively low and Lact signal is present. The ${ }^{1} \mathrm{H}$ MR spectra of the whole lesion and its mostly hypointense center, upscaled with a factor of 4.5 to correct for the difference in MRS voxel size, are shown in Fig. 3. In the center of the lesion, the levels of $\mathrm{Cr}$ and NAA are very low and Lact (the inverted doublet at about 1.27 and $\mathbf{1 . 3 8}$ ppm) twice as high as in the lesion containing voxel. Alanine, reportedly present in meningiomas measured under comparable experimental conditions $(16,17)$, was detected in none of the 18 MRS examined brain metastases of mammary carcinoma.

\section{Choline and Creatine}

For lesions larger than $50 \%$ of the MRS voxel size (eight out of 18) significant correlation was found between (total) Cho level and the lesion MRI signal after administration of Gd-DTPA ( $r=0.86 ; P<0.01$ ). Inclusion of smaller lesions leads to loss of correlation which may be attributed to dilution of results due to higher normal tissue contributions. Correlations between $\mathrm{Cr}$ level and either Gd-DTPA enhancement, lesion size, or Cho level were not found. 

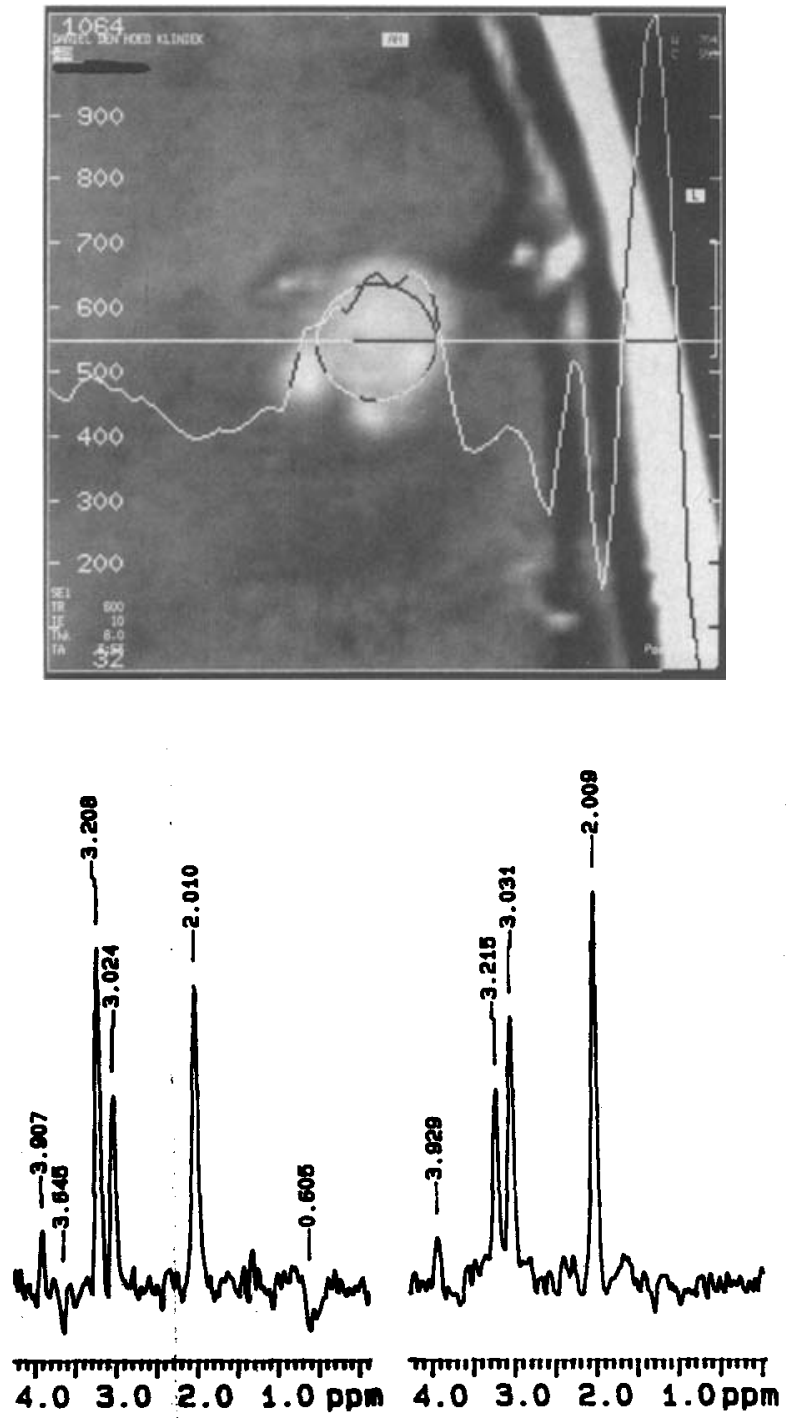

FIG. 1. ${ }^{1} \mathrm{H}$ MR spectrum of $8 \mathrm{~cm}^{3}$ voxel containing medium-sized brain metastasis of mammary carcinoma (left side) scaled relative to the spectrum of occipital control voxel (right side) and axial $T_{1}$-weighted MR image (SE 600/10) showing circular ROl covering half the Gd-DTPA enhanced area (Case 2). MRI signal intensity (arbitrary units) is shown for an arbitrary trace through the L-parietal lesion. Spectral assignments: Cho 3.21, Cr 3.02 and 3.91, and NAA 2.01 parts per million relative to tetramethylsilane.

\section{Correcting for Partial Volume Effects}

Partial volume effects, the lesions being smaller than the voxels measured by ${ }^{1} \mathrm{H}$ MRS, obscure the characterization of metastases of mammary carcinoma. Because NAA is generally accepted to be localized in neurons $(11,27)$, it is reasonable to assume that brain metastases do not contain NAA. When a second assumption is made, that the NAA in the spectra comes with normal brain tissue Cho and Cr signals in a ratio of 2:1:1 (roughly the proportions obtained in occipital brain lobe and in corpus nuclei caudati of volunteers), the net lesion metabolite levels can be calculated: "Lesion Cho" = Cho $-1 / 2$ NAA, "Lesion Cr" = Cr - 1/2NAA, "lesion Lact" = Lact. Postcontrast MRI signal is corrected for partial volume effects
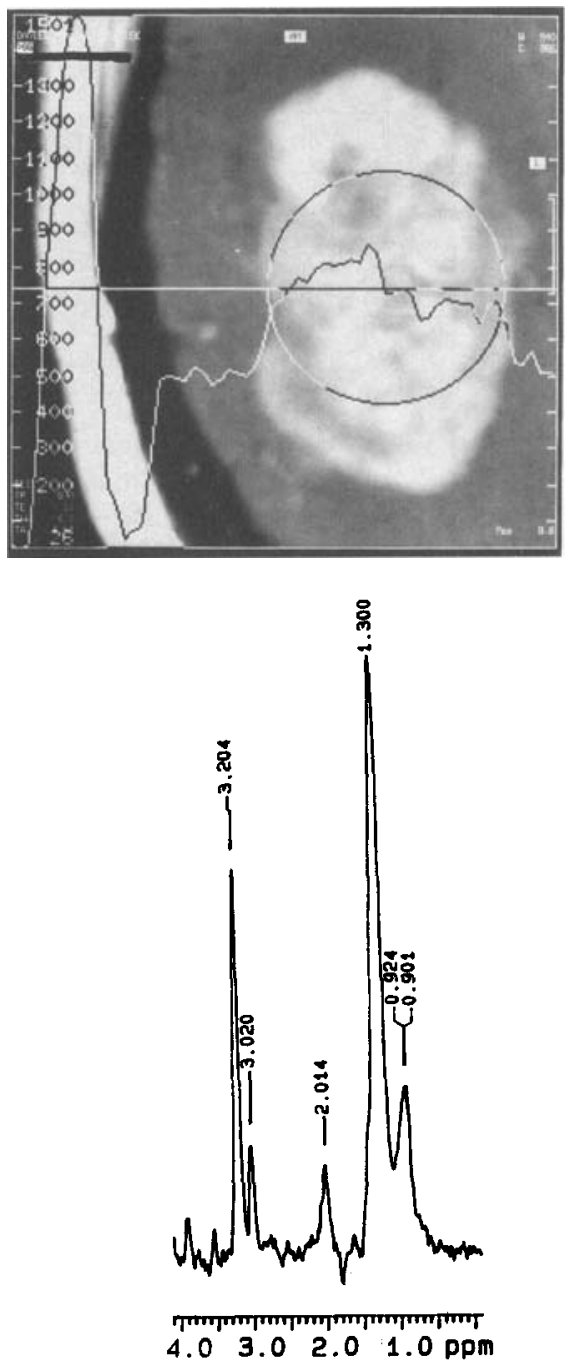

FIG. 2. ${ }^{1} \mathrm{H}$ MR spectrum of $18 \mathrm{~cm}^{3}$ voxel containing large brain metastasis of mammary carcinoma (Case 4a) and axial $T_{1}$ weighted MR image after Gd-DTPA administration (SE 600/10) showing a profile through the R-temporal lesion. In addition to Cho, $\mathrm{Cr}$, and NAA, there are lipid signals at 0.9 and $1.3 \mathrm{ppm}$.

by multiplication of the contrast with the filling factor:

Filling factor $\cdot$ Contrast $=\frac{(\text { Lesion volume })}{(\text { MRS voxel size })}$

(lesion MRI signal - control MRI signal) (control MRI signal)

with control MRI signal set at 100 .

After applying the above corrections on all lesions, a significant positive correlation between the lesion Cho signal ("Lesion metabolite level $=$ Cho" in Table 1) and the postcontrast MRI signal is found. The resulting linear regression is shown in Fig. $4(r=0.69, P<0.002 ; n=18)$. Lesion metabolite signals per unit of MRI visualized lesion volume are shown in the right-most columns of Table 1, "lesion metabolite level/filling factor." In the four lesions showing the weakest MRI enhancement (to intensities of $-13 \%$ to $+17 \%$ relative to normal brain tissue), the thus calculated Cho levels are not significantly higher than contralateral Cho (Cases 3a, 3b, 10, 14). 

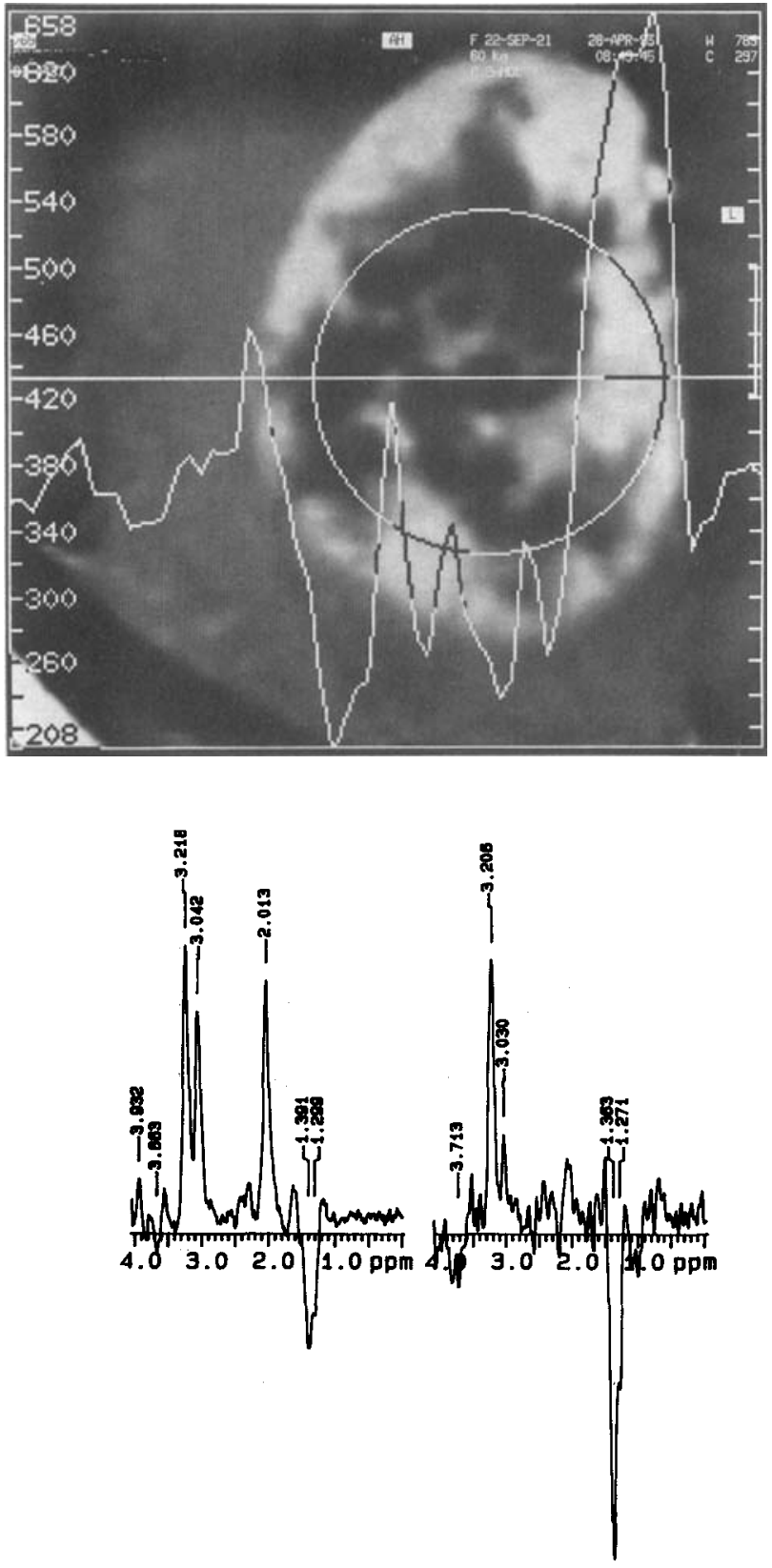

FIG. 3. ${ }^{1} \mathrm{H}$ MR spectra of $36 \mathrm{~cm}^{3}$ voxel containing large brain metastasis of mammary carcinoma and of $8 \mathrm{~cm}^{3}$ voxel positioned in the largely hypointense center of the same lesion (the latter spectrum upscaled by a factor of 4.5) and axial $T_{1}$-weighted image after Gd-DTPA administration (SE 600/10) showing a profile through the R-parietal lesion (Case 14). In addition to $\mathrm{Cho}, \mathrm{Cr}$, and NAA, there are Lact doublets at 1.27 and 1.38 ppm.

\section{Lactate}

Quantitation of Lact was straightforward in the majority of lesions where lipid signals were absent or low (13 out of 18). The MR spectra of the other five lesions showed intense lipid signals in phase with the Cho, $\mathrm{Cr}$, and NAA signals (i.e., Case 4a, Fig. 2) without a trace of inverted doublet Lact signal (1.32 ppm) interfering with the comparatively broad $-\mathrm{CH}_{2}$ - lipid resonance (1.3 ppm). The Lact coupling constant of $7 \mathrm{~Hz}$ and the water line width of at most $6 \mathrm{~Hz}$ achieved in the local shimming of any

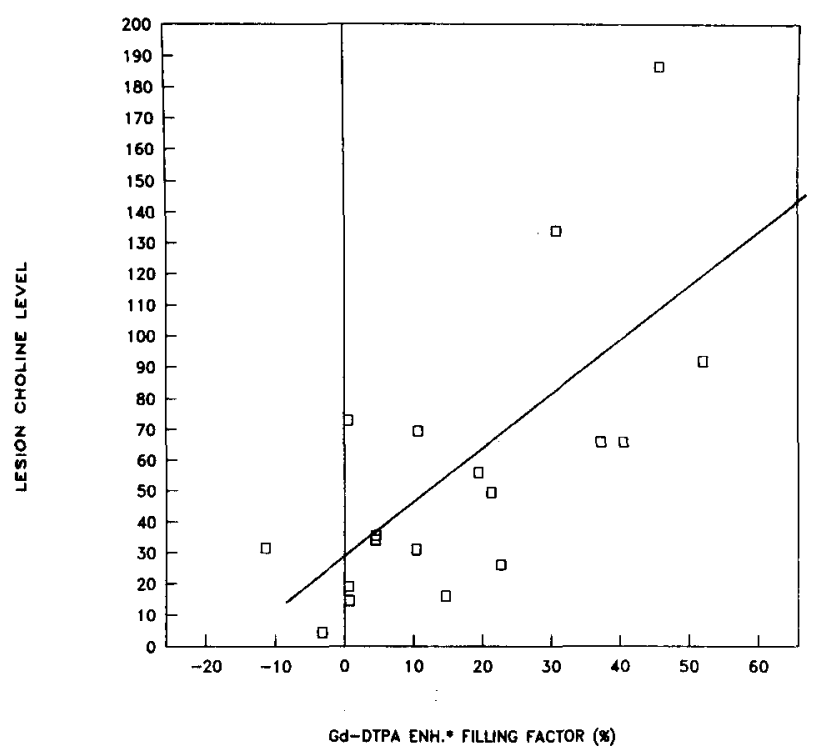

FIG. 4. Lesion Cho level plotted against the product of the GdDTPA enhancing voxel fraction and lesion contrast (Gd-DTPA enh.* filling factor (\%)). Linear regression analysis: $r=0.69, P<0.002$; $n=18$ ).

metastasis containing voxel (see Materials and Methods section), make the possibility of significant amounts of Lact not being recognized and confused with lipid signal highly unlikely. Compromising of any Lact level listed in Table 1, also the zeros in Cases 4a, 8, 11, and 13ab, by the presence of lipid is therefore negligible. Lact was detected in heterogeneously enhancing lesions (Cases 3a, $10,12,14)$, most of which had comparatively low Cho levels (Cases 3a, 10, 14) and very low $\mathrm{Cr}$ levels (Cases 3a, 10, 12).

\section{DISCUSSION}

For lesions larger than $50 \%$ of MRS voxel size (8/18), there was significant correlation between Gd-DTPAenhanced MRI signal and MRS-detected choline (Cho) signal ( $r=0.86, P<0.01$ ). The observed loss of correlation when including the smaller lesions was overcome by correcting for partial volume effects $(r=0.69, P<0.002$, $n=18$; Fig. 4). The knowledge that Cho and other metabolites are not detected in fully necrotic tissue, warrants the conclusion that our data do not support the hypothesis that necrotic tissues are specifically enhanced with Gd-DTPA $(4,7,8)$, but to the contrary confirm that the necrotic regions in tumors show up as hypointense areas $(9,10)$.

Significant linear correlation between total lesion volume, as determined from postcontrast MRI, and signal heterogeneity was shown $(r=0.59, P<0.02 ; n=18)$. Lact was only observed in large heterogeneously enhancing (ring-enhancing) metastases (Cases 3a, 10, 12, and 14) and with preference for the lesion center (Case 14; Fig. 3). This implies that Lact is only present in late stage lesions that contain large necrotic regions. The comparatively low lesion $\mathrm{Cr}$ and Cho levels at that stage are in line with 
reduced Cho levels in necrotic high-grade gliomas compared with solid high-grade gliomas (20). We conclude that in brain metastases of mammary carcinoma, the cancer cells do not preferentially ferment glucose to Lact, in other words the "Warburg effect" $(28,29)$ does not apply. The detected Lact is a product of ischemia preceding/ during tissue decay and the formation of central necrosis and does not reflect tumor-specific metabolism resulting in increased glycolysis.

These results are in agreement with suggestions that Lact might be concentrated in necrotic tissue $(13,16)$ and contradict a reported correlation of the presence of Lact in intracranial tumors with high Cho levels and increased glucose uptake (18). In our experience edema is characterized by normal Cho and $\mathrm{Cr}$ levels and NAA reduced by up to $50 \%$ (compared with normal brain tissue) and, in contrast to an assumption published by others (22), by absence of Lact signal. The presented lesion metabolite signals have not been corrected for the (not easily quantifiable) amount of edema rather than normal brain tissue included in the MRS voxels. In the volume-corrected lesion metabolite levels, it has been assumed that the whole lesion is visualized with Gd-DTPA-enhanced MRI (last columns in Table 1). The unlikely high Cho and $\mathrm{Cr}$ levels in two of the smallest lesions might be interpreted as evidence that early stage brain metastases of mammary carcinoma are only partially visualized with Gd-DTPAenhanced MRI (Cases 4b, 5).

This study has contributed both to understanding of tumor pathophysiology and to the evolving science of metabolic fingerprinting of pathophysiological processes by MRS. In characterizing metastatic brain tumors, generally small lesions when detected for the first time, single voxel ${ }^{1} \mathrm{H}$ MRS is a perfectly feasible method if not the method of choice. Only in four out of 18 lesions studied, those exceeding $2.5 \mathrm{~cm}$ diameter (Cases $4 \mathrm{a}, 10$, $12,14)$, spectroscopic imaging with a volume resolution of $1 \mathrm{~cm}^{3}$ would have yielded additional information regarding tumor heterogeneity.

\section{ACKNOWLEDGMENTS}

Some of the presented data are part of the "Clinical Trial Proton Spectroscopy" initiated by Dr. R. Sauter, Siemens AG, Erlangen, Germany. The authors thank D.J.A. Kraus for his participation in the collection of the data.

\section{REFERENCES}

1. S. W. Atlas, Intraaxial brain tumors, in "Magnetic Resonance Imaging of the Brain and Spine" (S. W. Atlas, Ed.), pp. 223-326, Raven Press, New York, 1991.

2. A. D. Watson, S. M. Rocklage, M. J. Carvlin, Contrast agents, in "Magnetic resonance imaging" (D. D. Stark, W. G. Bradley, Jr, Eds.), pp. 372-437, Mosby-Year Book, Inc., St Louis, 1992.

3. S. Saini, B. Hamm, Contrast enhanced MRI, in "Clinical Magnetic Resonance Imaging” (R. R. Edelman, J. R. Hesselink, Eds.), pp. 237-271, W. B. Saunders Company, Philadelphia, 1990.
4. R. C. Brasch, H-J. Weinman, G. E. Wesbey, Contrastenhanced NMR imaging: animal studies using gadolinium DTPA complex. Am. J. Roentgenol. 142, 625-630 (1984).

5. M. R. Sage, Blood-brain barrier: phenomenon of increasing importance to the imaging clinician. Am. J. Roentgenol. 138, 887-898 (1982).

6. D. G. Gadian, J. A. Payne, D. J. Bryant, I. R. Young, D. H. Carr, G. M. Bydder, Gadolinium-DTPA as a contrast agent in MR imaging; theoretical projections and practical observations. J. Comput. Assist. Tomogr. 9, 242-251 (1985).

7. J. C. Wu, E. C. Wong, Y. A. Sidky, J. S. Hyde, E. C. Borden, A. Jesmanowicz, D. J. Lindner, High resolution contrast enhancement pharmatokinetic analysis of a developing murine tumor, in "Proc, SMRM, 10th Annual Meeting, San Francisco, 1991," p. 866.

8. B. H. Cohen, E. Bury, R. J. Packer, L. N. Sutton, L. T. Bilaniuk, R. A. Zimmerman, Gadolinium-DTPA-enhanced magnetic resonance imaging in childhood tumors. Neurology 39, 1178-1183 (1989).

9. G. Brix, W. Semmler, R. Port, L. R. Schad, G. Layer, W. J. Lorenz, Pharmacokinetic parameters in CNS Gd-DTPA enhanced MR imaging. J. Comput. Assist. Tomogr. 15, 621-628 (1991).

10. M. E. Healy, J. R. Hesselink, G. A. Press, M. S. Middleton, Increased detection of intracranial metastases with intravenous Gd-DTPA. Radiology 165, 619-624 (1987).

11. B. L. Miller, A review of chemical issues in ${ }^{1} \mathrm{H}$ NMR spectroscopy: N-acetyl-L-aspartate, creatine and choline. NMR Biomed. 4, 47-52 (1991).

12. J. R. Alger, J. A. Frank, A. Bizzi, M. J. Fulham, B. X. Desouza, M. O. Duhaney, S. J. Inscoe, J. L. Black, P. C. M. van Zijl, C. T. W. Moonen, G. Di Chiro, Metabolism of human gliomas: assessment with H-1 MR spectroscopy and F-18 fluorodeoxyglucose PET. Radiology 177, 633-641 (1990).

13. D. L. Arnold, E. A. Shoubridge, J.-G. Villemure, W. Feindel W, Proton and phosphorus magnetic resonance spectroscopy of human astrocytomas in vivo; preliminary observations of tumor grading. NMR Biomed. 3, 184-189 (1990).

14. H. Bruhn, J. Frahm, M. L. Gyngell, K. D. Merboldt, W. Haenicke, R. Sauter, C. Hamburger, Noninvasive differentiation of tumors with use of localized H-1 MR spectroscopy in vivo: initial experience in patients with cerebral tumors. Radiology 172, 541-548 (1989).

15. P. Demaerel, K. Johannik, P. Van Hecke, C. Van Ongeval, S. Verellen, G. Marchal, G. Wilms, C. Plets, J. Goffin, F. Van Calenbergh, M. Lemmens, A. L. Beart, Localized 'H NMR spectroscopy in fifty cases of newly diagnosed intracranial tumors. J. Comput. Assist. Tomogr. 15, 67-76 (1991).

16. S. S. Gill, D. G. T. Thomas, N. Van Bruggen, D. G. Gadian, C. J. Peden, J. D. Bell, I. J. Cox, D. K. Menon, R. A. Iles, D. G. Bryant, G. A. Coutts, Proton MR spectroscopy of intracranial tumours: in vivo and in vitro studies. J. Comput. Assist. Tomogr. 14, 497-504 (1990).

17. H. Kugel, W. Heindel, R.-I. Ernestus, J. Bunke, R. du Mesnil, G. Friedmann, Human brain tumors: spectral patterns detected with localized H-1 MR spectroscopy. Radiology 183, 701-709 (1992).

18. P. R. Luyten, A. J. H. Marien, W. Heindel, P. H. J. van Gerwen, K. Herholz, J. A. den Hollander, Metabolic imaging of patients with intracranial tumors: H-1 MR spectroscopic imaging and PET. Radiology 176, 791-799 (1990).

19. R. Sauter, W. Loeffler, H. Bruhn, J. Frahm, The human brain: localized H-1 MR spectroscopy at 1.0 T. Radiology 176, 221224 (1990).

20. M. J. Fulham, A. Bizzi, M. J. Dietz, H. H. L. Shih, R. Raman, G. S. Sobering, J. A. Frank, A. J. Dwyer, J. R. Alger, G. Di 
Chiro, Mapping of brain tumor metabolites with proton MR spectroscopic imaging: clinical relevance. Radiology 185, 675-686 (1992).

21. C. M. Segebarth, D. F. Baleriaux, P. R. Luyten, J. A. den Hollander, Detection of metabolic heterogeneity of human intracranial tumors in vivo by ${ }^{1} \mathrm{H}$ NMR spectroscopic imaging. Magn. Reson. Med. 13, 62-76 (1990).

22. D. Ott, J. Hennig, T. Ernst, Human brain tumors: assessment with in vivo proton MR spectroscopy. Radiology 186, 745752 (1993).

23. J. Frahm, K. D. Merboldt, W. Haenicke, Localized proton spectroscopy using stimulated echoes. J. Magn. Reson. 72, 502-508 (1987).

24. D. Hentschel, R. Ladebeck, Quantitative in vivo ${ }^{1} \mathrm{H}$-spectroscopy of healthy and tumorous human brain tissue at 4 tesla. Appl. Magn. Reson. 1, 41-46 (1990).
25. C. H. Sotak, D. M. Freeman, A method for volume-localized lactate editing using zero-quantum coherence created in a stimulated-echo pulse sequence. J. Magn. Reson. 77, 382388 (1988).

26. J. H. Duijn, G. B. Matson, A. A. Maudsley, J. W. Hugg, M. W. Weiner Human brain infarction: proton MR spectroscopy. Radiology 183, 711-718 (1992).

27. D. L. Birken, W. L. Oldendorf, N-acetyl-L-aspartic acid: a literature review of a compound prominent in ${ }^{1} \mathrm{H}-\mathrm{NMR}$ spectroscopic studies. Neurosci. Biobehav. Rev. 13, 23-31 (1989).

28. O. Warburg, Experiments on surviving carcinoma tissue; methods. Biochem. Ztsch. 142, 317-350 (1923).

29. E. Racker, M. Spector, Warburg effect revisited: merger of biochemistry and molecular biology. Science 213, 303-307 (1981). 